\title{
ECOLOGICAL RESTORATION STATUS INDEX FOR EVALUATING THE RESTORED COAL GANGUE PILE: A CHRONOSEQUENCE STUDY BASED ON THE PLANT-SOIL SYSTEM IN THE SHANXI MINING AREA, CHINA
}

\author{
HAO, J. ${ }^{1}-$ GUO, D. G. ${ }^{2}-$ LI, H. Y. ${ }^{*}-$ MENG, W. Q. ${ }^{3}$ \\ ${ }^{1}$ College of Environmental Science and Engineering, Nankai University, 38 Tong Yan Road, \\ Jinnan District, Tianjin 300350, China \\ (e-mail: haojing1987.happy@163.com; phone: +86-178-2201-5686)
}

${ }^{2}$ College of Environment and Resource, Shanxi University, 92 Wu Cheng Road, Xiaodian District, Taiyuan 030006, China

${ }^{3}$ College of Urban and Environmental Science, Tianjin Normal University, 393 Binshui West Road, Xiqing District, Tianjin 300387, China

*Corresponding author

e-mail: eialee@nankai.edu.cn

(Received 22 $2^{\text {nd }}$ Apr 2019; accepted $12^{\text {th }}$ Jul 2019)

\begin{abstract}
This study was carried out to evaluate ecological restoration status of restored coal gangue pile in Shanxi Province, China, using ecological restoration status index (ERSI) based on a dynamic plant-soil system. ERSI was a unitless value that indicated the status of ecological restoration in the restored site. Five-year dynamics of the plant-soil system were monitored in the restored coal gangue pile at Sima Coal Mine of Lu'an Group, Changzhi, Shanxi, China, from 2009 to 2013. The fixed plots were established based on the chronosequence (space-for-time). The natural secondary community was selected as the reference site. The parameter system for evaluation of ecological restoration status was established on the basic characteristics of the plant community and soil physicochemical properties. Principal component analysis (PCA) was employed to derive ERSI. The first year was taken as the benchmark year. Except for year 2, the ecological restoration status in years 3 to 5 of the recovery and reference site were better than that in the benchmark year. Overall, the ERSI value increased with recovery age during the early stage of recovery. With recovery age, the uncertainty of ERSI showed decreased trend by Monte Carlo simulation (MCS).
\end{abstract}

Keywords: ecological restoration status index, soil property, plant community, Monte Carlo, early stage

\section{Introduction}

Soil properties and plant community characteristics are two critical milestones of any restoration plan (Orozco-Aceves et al., 2017; Li and Liber, 2017). In a plant-soil system, plants and soil are interdependent (Krumins et al., 2015). Soil development is necessary to support plant growth (Orozco-Aceves et al., 2017). In turn, plant growth can improve the soil properties (Ahirwal et al., 2017; Li and Liber, 2017). Therefore, it is essential to evaluate the ecological restoration status through both aspects of plant and soil. How should the parameter system of ecological restoration status evaluation based on a plant-soil system be established for a restored site? How should the restoration status of a restored site in every year of recovery be scientifically evaluated? These questions are still debated by researchers of restoration ecology. Thus, many current situation evaluations of ecological restoration status (Rossini-Oliva et al., 2016) have been reported, but they are insufficient dynamic evaluations of ecological restoration 
status base on chronosequence. Moreover, these current situation evaluations have mostly focused on a particular aspect of the plant-soil system, such as plant community characteristics or soil physical or chemical properties (Gomez-Ros et al., 2013) but are insufficient when aiming at the plant-soil system.

Many evaluation parameters including qualitative parameters (e.g., habitat complexity) and quantitative parameters (e.g., vegetation coverage) have been presented. There are some recognized evaluation parameters, such as species diversity, plant biomass, vegetation coverage, soil density, total porosity, field capacity, organic matter content, TN, available nitrogen, total phosphorus, AP, and $\mathrm{pH}$ (Ott and Van Aarde, 2014; Licina et al., 2013; Parraga-Aguado et al., 2013; Anawar et al., 2013; Bodlák et al., 2012). However, the parameters of basic plant community characteristics (such as the index of growth and decline of species, community similarity, and community stability) are insufficient for ecological restoration status evaluation. The parameter system of evaluation for ecological restoration status is still not systemic (Liu, 2011).

Evaluation methods are varied. Single evaluation methods and combination evaluation methods are usually used for evaluations. The analytic hierarchy process (AHP), fuzzy comprehensive evaluation method (FCE), principal component analysis (PCA), clustering analysis and gray correlation evaluation, among others (Gomez-Ros et al., 2013), are single evaluation methods. AHP-FCE, PCA-AHP, and PCA-TOPSIS (Hao et al., 2016; Zhao et al., 2014; Bouzon et al., 2016) are combination evaluation methods. Based on the way of determining the weight of parameters, these methods are divided into three categories: subjective assignment value (e.g., experts scoring method, AHP), objective assignment value (e.g., PCA, entropy value method), and comprehensive assignment value (e.g., FCE). These methods include the following three features in selecting recovery goals for ecological restoration status evaluation.

Take existing standards as the recovery goal. Zhang et al. (2007) took the figure of 1/100 land resources in the People's Republic of China as a grading standard. The soil suitability evaluation hierarchy of vegetation restoration in a coal gangue pile was divided into 4 levels: very suitable, suitable, barely suitable, and temporarily not suitable. By referring to the degree of land desertification, soil wind erosion intensity grading and the secondary general survey of soil data, Yao and Yang (2014) divided the degree of mine ecological restoration status into four levels: perfect, fine, average, and low.

Take a certain ideal status as the recovery goal. Zhao et al. (2014) set evaluation grades with a relatively proximity degree between soil quality and the worst state. The closer the value was to 1 , the closer to the ideal evaluation object and the higher the evaluation grade were, but the lower the evaluation level was.

Take natural secondary communities or communities without human disturbance as the main recovery goal. Lacking long-term dynamic monitoring and mechanism research of the plant-soil system (Tripathi et al., 2016), these recovery goals are unscientific to some extent (Mark et al., 2012). Whether these recovery goals are optimal is usually questionable.

The evaluation of ecological restoration status based on plant-soil systems is important to estimate the restoration status of restored sites, so establishing a parameter system for the ecological restoration status is essential (Pietrzykowski and Chodak, 2014). In the present research, the parameter system was established on the basic plant community characteristics and soil physicochemical properties. Based on the parameter 
system, an integrated 'ecological restoration status index (ERSI)' could be developed by principal component analysis and used to evaluate the ecological restoration status quantitatively based on the chronosequence in a restored coal gangue pile. Moreover, the first year was taken as the benchmark year, the recovery goal was not specifically selected. It will be expected that if the ERSI value in one year is below that of the benchmark year, the ecological restoration status in this year is worse than the benchmark. Conversely, if the ERSI value in another year is above that of the benchmark year, the ecological restoration status in this year is better than the benchmark (Mukhopadhyay et al., 2014). It was predicted that the ERSI value would increase with recovery age in the early stage of recovery (Mukhopadhyay et al., 2014; Orozco-Aceves et al., 2017; Hao et al., 2015). This study was carried out to evaluate ecological restoration status of restored coal gangue pile in Shanxi Province, China, using ERSI based on a dynamic plant-soil system.

\section{Material and methods}

\section{Study site}

The study site is representative ecological restoration area in north of China. The study was conducted in the restored coal gangue pile at Sima Coal Mine of Lu'an Group, Changzhi, Shanxi, China, from 2009 to 2013 (Fig. 1a). The climate is temperate, with a $9{ }^{\circ} \mathrm{C}$ mean and a $-29{ }^{\circ} \mathrm{C}$ minimal annual temperature. The frost-free period is 160 days. The annual rainfall is approximately $340 \mathrm{~mm}$ to $833 \mathrm{~mm}$, and the annual evaporation capacity is approximately $1,558 \mathrm{~mm}$. The original soil type was loess-like calcareous soil. The soil erosion modulus was from 500 to $1,000 \mathrm{t} \cdot\left(\mathrm{km}^{2} \cdot \mathrm{a}\right)^{-1}$. The original landforms were mainly ravines covered by native secondary plants, such as Bothriochloa ischaemum, Artemisia lavandulaefolia, and Melilotus officinalis (Fig. 1b).

The fixed plots were established based on the chronosequence (space-for-time) (Mudrák et al., 2016; Alvey et al., 2003; Elgersma, 1998; Hao et al., 2016). The restored coal gangue pile consisted of three platforms with a stair-step shape established in 2009 , 2010 and 2011 (Fig. 1c). The area of each platform was $1,500 \mathrm{~m}^{2}(50 \mathrm{~m}$ long, $30 \mathrm{~m}$ wide). The total area of the three platforms was $4,500 \mathrm{~m}^{2}$. The altitude difference between adjoining platforms was $10 \mathrm{~m}$. The restoration procedure included forming and leveling the surface of each platform. During the forming process, the coal gangue layer and soil layer were alternated in stacking. Above each coal gangue layer, there was a soil layer. The thickness of each coal gangue layer was $3 \mathrm{~m}$. The thickness of each soil layer was $50 \mathrm{~cm}$. The last layer was the soil layer with a thickness of $80 \mathrm{~cm}$. The soil was taken from the surrounding loess-like calcareous soil. After leveling the surface of each platform, Populus tomentosa (no canopy, $3.5 \mathrm{~m}$ height) was grown on each platform. The distances between the arbors and rowledges were $1.5 \mathrm{~m}$ and $2 \mathrm{~m}$, respectively. Herbs maintained spontaneous recovery after trees were planted.

There were three sample plots. Each sample plot $\left(400 \mathrm{~m}^{2}\right)$ consisted of 16 tree subsamples (area of each tree subsample $=25 \mathrm{~m}^{2}$ ) established at the middle of each platform (Fig. 1d). 48 tree subsamples were set. An area of $1 \mathrm{~m}^{2}$ was set at the left corner of each subsample for the herb sample. Each sample plot consisted of 16 herb samples. 48 herb samples were set. The reference site was a native secondary community with dominate species Artemisia brachyloba. The distance between the reference site and the restored coal gangue pile was approximately 1,000 $\mathrm{m}$. Six samples (area of each sample $=25 \mathrm{~m}^{2}$ ) were in the reference site on the north of the coal 
gangue pile using GPS. The contents of investigation including basic plant community characteristics, soil physical properties and soil chemical properties in each sampling unit were repeated each year during the summer (August) from 2011 to 2013.

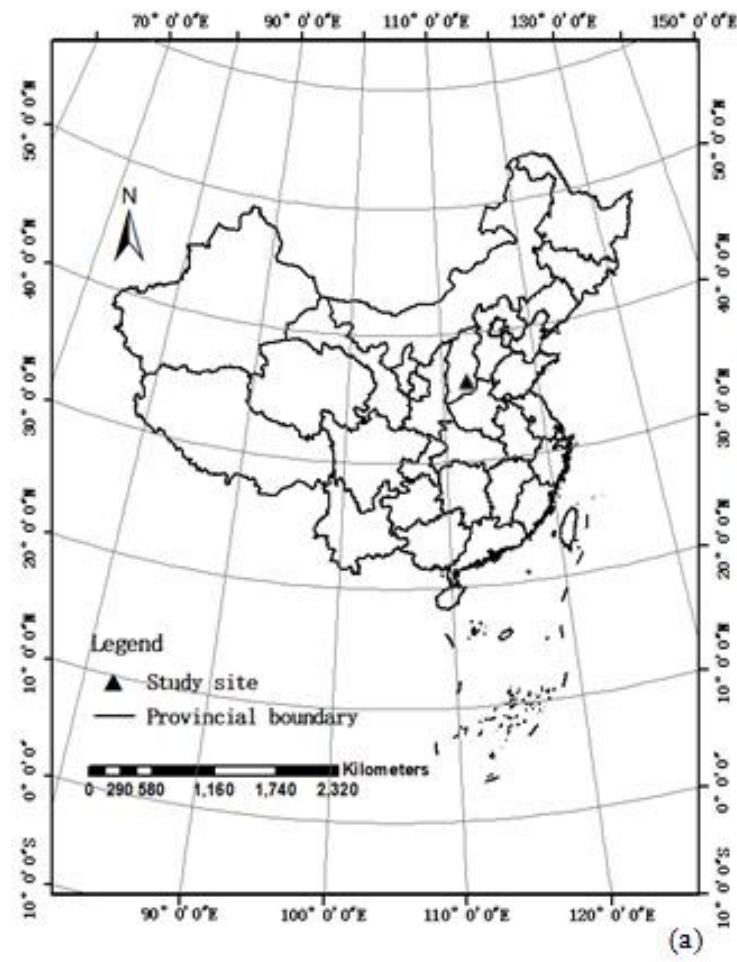

(a)

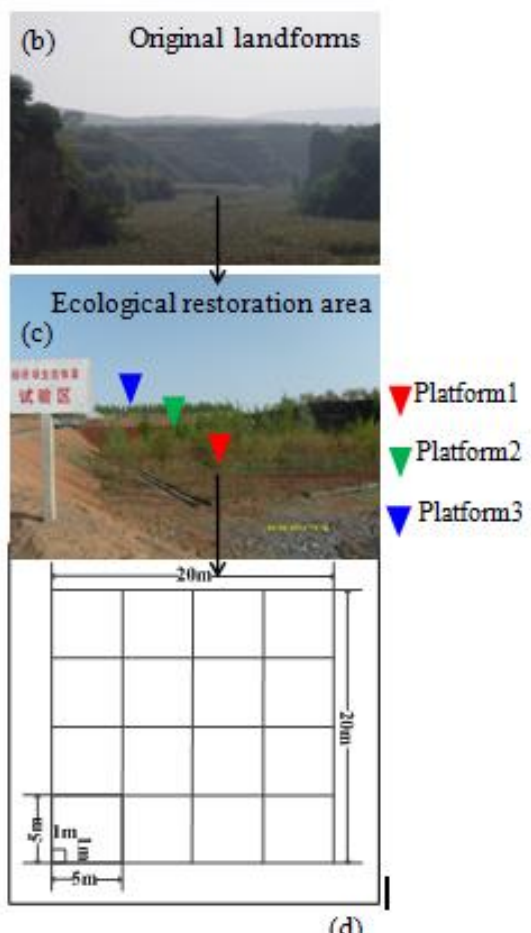

(d)

Figure 1. Locations and design of experimental plots. (a) Location of study site in China. (b) Original landforms of study site. (c) Ecological restoration area. Red triangle: platform1 established in 2009. Green triangle: platform 2 established in 2010. Blue triangle: platform3 established in 2011. (d) Design of experimental plots in each platform

\section{Plant community}

The basic characteristics of the plant community, including the diameter at breast height $(\mathrm{DBH})$ of trees, plant species, height, canopy, and coverage, were investigated. Twelve typical sampling units (area of each typical sample $=1 \mathrm{~m}^{2}$ ) were set on each platform and the reference site to obtain the herbal biomass. All herbal bodies were harvested, placed in sealed bags, cleaned, and dried to a constant weight at $80{ }^{\circ} \mathrm{C}$ in the incubator. The dry weights of the herb were determined by electronic scales (accuracy $0.01)$.

The integrity of the vertical structure (IVS) was assigned 1,2 and 3: 1 means the vertical structure has only one layer; 2 means the vertical structure has two layers; and 3 means the vertical structure has three layers.

The species richness index (SRI) was assigned a value according to the species evenness and dominance of a community (Table 1).

The index of the growth and decline of species (IGDS) indicates the dynamic of immigration and emigration of plant species in a community. If the index of growth and decline of species is close to 1.00, growth and decline maintain a dynamic balance. In the present study, taking the first year as the benchmark, the index of growth and 
decline of species was determined by the net immigration rate in year 1 and is set equal to 100 (Eqs. 1-3).

$$
\begin{gathered}
\text { IGDS }_{j}=I_{j} / E_{j}(j=2,3,4,5)\left(\text { If } j=1, C_{1}=100\right) \\
I_{j}=\frac{N_{I j}}{N_{1}} \times 100 \%(j=2,3,4,5) \\
E_{j}=\frac{N_{E j}}{N_{1}} \times 100 \%(j=2,3,4,5)
\end{gathered}
$$

where $j$ is a plant community, $I G D S_{j}$ is the index of growth and decline of species for community $j, I_{j}$ is the net immigration rate of community $j$ compared to the benchmark, $E_{j}$ is the net emigration rate of community $j$ compared to the benchmark, $N_{I j}$ is the number of immigration species of community $j$ compared to the benchmark, $N_{E j}$ is the number of emigration species of community $j$ compared to the benchmark, and $N_{l}$ is the number of species of the benchmark year (year 1).

Table 1. The assignment and implication for index of species richness

\begin{tabular}{c|c}
\hline Assignment & Implication \\
\hline 1 & Obvious dominant species, worse species evenness \\
2 & Obvious dominant species, better species evenness \\
3 & Unobvious dominant species, worse species evenness \\
4 & Unobvious dominant species, better species evenness \\
\hline
\end{tabular}

Index of species evenness $<0.95$ means worse species evenness; $>0.95$ means better species evenness

The value of community similarity (VCS) was determined by the Jaccard similarity index, which means the similarity of species between community $A$ and community $B$ (Eq. 4).

$$
\operatorname{VCS}=\frac{c}{(a+b-c)} \times 100 \%
$$

where $a$ is the number of species for community $A, b$ is the number of species for community $B$, and $c$ is the number of species in common between communities $A$ and $B$.

The index of community stability (ICS) was determined by M. Godron's stability determination method (Godron, 1972).

\section{Soil property}

In each platform, eight big samples $\left(25 \mathrm{~m}^{2}\right)$ were selected and located by GPS. Three typical samples of topsoil $(0-20 \mathrm{~cm})$ were collected after clearing away the surface litter in each big sample. Each typical sample consisted of three subsamples (area of each subsample $=0.04 \mathrm{~m}^{2}$ ). The subsamples were in the typical sample point approximately $20 \mathrm{~cm}$ and mixed thoroughly. There were eight replicates in each platform. The sampling was carried out each year from 2011 to 2013 during the summer. Moreover, in the summer of 2011, three typical contrasted sampling units were established in every big sample at the reference site. Each typical sample consisted of three subsamples (area 
of each subsample $=0.04 \mathrm{~m}^{2}$ ). Eight replicates were carried out in each platform. These typical soil samples were air-dried and used for physical and chemical analysis. Soil moisture (SM) content, soil field capacity (SFC), and soil density (SD) were determined according to Xie et al. (2012). Soil total porosity (STP) was calculated according to Zhang (2006). The contents of soil total organic carbon (STOC), soil organic matter (SOM), readily oxidized organic carbon (ROOC), particulate organic carbon (POC), total nitrogen (TN), available phosphorus (AP), available potassium (AK), and soil $\mathrm{pH}$ were determined according to Su (2010).

\section{Ecological restoration status index (ERSI)}

In this research, Principal component analysis (PCA) was used to calculate the weight of each parameter and select the major parameters. Principal components (PCs) that had an eigenvalue $\geq 1$ and that explained at least $5 \%$ of the variation of the data were selected. On each particular principal component (PC), the highly weighted parameters (absolute value) were considered very important and chosen for the ecological restoration status index (ERSI). ERSI was a unitless value (from 0 to 1 ) that indicated the status of ecological restoration in the coal gangue pile (Mukhopadhyay et al., 2014). It is expected that if the ERSI value is higher, the ecological restoration status is superior (Mukhopadhyay et al., 2014). In this study, the first year of recovery was taken as the benchmark year. By comparing the ERSI value in every year of recovery to that in the benchmark year, the ecological restoration status was evaluated. The final ERSI equation is as follows (Eq. 5):

$$
E R S I=\sum_{i=1}^{n} W_{i} S_{i}
$$

where $i$ is the number of parameters, $W_{i}$ is the normalized weight value $\left(w_{i}\right)$ of parameter $i, \sum_{i=1}^{n} W_{i}=1, S_{i}$ is the normalized value of parameter $i$, and $W_{i} S_{i}$ is the contribution of parameter $i$ on the calculated ERSI.

The $W_{i}$ equation is as follows (Eq. 6):

$$
W_{i}=w_{i} / \sum_{i=1}^{n} w_{i}
$$

where $w_{i}$ is the weight value of parameter $i$ by PCA, and $\sum_{i=1}^{n} w_{i}$ is the total weight value of the major parameters selected by PCA; this $W_{i}$ equation was used to normalize the weight value of parameter $i$.

The $S_{i}$ equation is as follows (Eq. 7):

$$
S_{i}=a /\left[1+\left(x_{i} / x_{i 0}\right)^{b}\right]
$$

This $S_{i}$ equation was used to convert the real values of the ecological restoration status parameters into unitless scores (from 0 to 1 ), where $x_{i}$ is the real value of parameter $i, x_{i o}$ is the mean value of parameter $i$ with all stages of recovery, and $a$ is the maximal score of the ecological restoration status property and is set equal to 1.00. In the real value range of each parameter (from minimum to maximum of the real value), the lower the value of the parameter, the better the development of the parameter, thus, $b$ was set equal to 2.5 . In turn, $b$ was set equal to -2.5 (Mukhopadhyay et al., 2014). The similar method described by Mukhopadhyay et al. (2014) aimed at mine soil quality and derived a mine soil quality index (MSQI). MSQI was derived based on the mine soil 
physical, chemical and biological parameters without the parameters of the plant community. In the process of mine ecological restoration, the interaction between mine soil and plant community always exists. ERSI involves not only the parameters of the mine soil physicochemical properties but also the parameters of basic characteristics of plant communities. The dynamic development of a mine plant-soil system could be expressed by ERSI.

\section{Monte Carlo simulation (MCS)}

Monte Carlo simulation (MCS) is a method to estimate uncertainty with the aid of computer software. This methodology provides an uncertainty value without any approximations or shortcuts (Zeng et al., 2018). In this research, MCS was used to analyze the uncertainty of the ERSI. Firstly, the means and standard deviations of parameters in each recovery age were calculated. Based on the current sample data and experiences, the distribution functions of parameters were defined. Then, ERSI was defined by the function of define forecast according to Equation 5. Finally, using the function of run preference, the number of simulation and sensitivity analysis were operated. ERSI values of each period were obtained. In this paper, 10000 simulations were conducted. The confidence level was $95 \%$.

\section{Statistical analysis}

PCA was completed by using Microsoft Excel and SPSS 11.5. The correlations and differences between variables were calculated according to Pearson's coefficient and Least-significant difference (LSD), respectively (Hao et al., 2015). A probability level of 0.05 was always used as the threshold for significance. MCS and sensitivity analysis were conducted by Crystal Ball software.

\section{Results}

\section{Plant community}

The dominant species of the herbal community were Artemisia lavandulaefolia (years 1 and 2), Puccinellia distans (year 3), Leymus chinensis (years 4 and 5), and Artemisia brachyloba (reference site). The coverage of the community achieved $80 \%$ in years 4 and 5. In previous research (Hao et al., 2016), overall, the average DBH of trees (ADT) (from 4.89 to $11.85 \mathrm{~cm}$ ), coverage of the herb layer (CHL) (from 35 to 80\%) and coverage of the community (CC) (from 40 to $80 \%$ ) increased with recovery age. The average ratio height and canopy of trees fluctuated due to the growth characteristics of Populus tomentosa. The average height of the herb layer (AHHL), total biomass of the herb layer (TBHL) and index of species diversity (ISD) also fluctuated due to the differences of dominant species and species components, which were expressed by the dynamics of immigration and emigration of plant species in a community. In years 4 and 5, IGDS maintained a dynamic balance (from 1.0 to 1.1). The community stability was worse. The vertical structure of the community always had two layers (tree and herb) from years 1 to 5 . From years 3 to 5, the index of species richness mainly remained 1, and the change of VCS mainly remained within 0.688-0.710. It was indicated that in years 1 to 2 , the species component changed significantly. However, in later years, the species component changed slightly with the promoted soil properties. 


\section{Soil physicochemical properties}

In previous research (Hao et al., 2015), overall, SM (from 4.095 to 2.860\%) and SD (1.603 to $1.243 \mathrm{~g} / \mathrm{cm}^{3}$ ) decreased with recovery age due partly to the worse water retaining capacity of the mine soil. Partly because the weathering of coal gangue strengthened gradually, STP, STOC, SOM, TN, AP, and AK increased (Sena et al., 2015). In addition, SFC deceased (from 21.2\% to 20.2\%) in years 1 to 3 but increased $(21.5 \%)$ in later years. POC contents decreased in year 2 and were $0.011-0.012 \mathrm{~g} / \mathrm{kg}$ in later years. The soil was alkaline due to aluminum ion exchanged through the weathering of coal gangue; $\mathrm{pH}$ values ranged from 8.50 to 8.03 and decreased with recovery age due to aluminum ion loss by rainfall. Significant differences of soil properties were shown between year 5 of recovery and the reference site $(P<0.05)$ (Hao et al., 2015).

\section{Correlation between plant and soil}

During the early stage of ecological restoration in the coal gangue pile, significantly negative correlation was shown between ADT and SM content $(P<0.05)$ (Table 2). CHL was significantly negatively correlated $(P<0.05)$ with SD. ISD was significantly positively correlated with POC $(P<0.05)$. IGDS was significantly negatively correlated with $\operatorname{STP}(P<0.05)$.

Table 2. Correlation between basic plant community characteristics and soil properties

\begin{tabular}{c|c|c|c|c|c}
\hline Parameter & ADT & CHL & CC & ISD & IGDS \\
\hline SM & $-0.921^{*}$ & - & - & - & - \\
SD & - & $-0.822^{*}$ & - & - & - \\
STP & - & - & - & - & $-0.812^{*}$ \\
STOC & $0.940^{*}$ & $0.903^{*}$ & $0.875^{*}$ & - & - \\
ROOC & $0.938^{*}$ & $0.930^{* *}$ & $0.903^{*}$ & - & - \\
POC & - & - & - & $0.850^{*}$ & - \\
pH & $-.923^{*}$ & $-0.852^{*}$ & $-0.814^{*}$ & - & - \\
AP & $0.916^{*}$ & $0.852^{*}$ & $0.832^{*}$ & - & - \\
AK & $0.951^{*}$ & $0.974^{* *}$ & $0.970^{* *}$ & - & - \\
\hline
\end{tabular}

The average DBH of trees (ADT), coverage of the herb layer (CHL), coverage of the community (CC), index of species diversity (ISD), the index of the growth and decline of species (IGDS), soil moisture (SM), soil density (SD), soil total porosity (STP), soil total organic carbon (STOC), readily oxidized organic carbon (ROOC), particulate organic carbon (POC), soil $\mathrm{pH}(\mathrm{pH})$, available phosphorus (AP) and available potassium (AK)

Note: ${ }^{*}$ Correlation is significant at the 0.05 level (2-tailed). ${ }^{* *}$ Correlation is significant at the 0.01 level (2-tailed).

\section{Ecological restoration status index (ERSI)}

Through principal component analysis, eigenvalues were above 1.0 in the first four principal components (PCs) (Table 3). Significant positive correlations were shown between principal component-1 (PC-1) and STOC, ROOC, TN, and AP (Fig. 2). The significant negative correlation was shown between PC-1 and $\mathrm{pH}$. STOC and ROOC, $\mathrm{pH}$ and TN were significant positively $(P<0.01)$ and negatively $(P<0.05)$ correlated, 
respectively. It was indicated that PC-1 represented the soil chemical properties. Under PC-2, ADT was highly weighted. ISD was highly weighted in PC-3. TBHL and SOM were highly weighted in PC-4. Given adequate time, the rich herb biomass can supply SOM. However, in this research, neither parameter showed significant correlation due to the limit of the recovery age (only five years). The percentage of cumulative explanation was $97.6 \%$ by nine parameters (ADT, TBHL, ISD, SOM, STOC, ROOC, $\mathrm{pH}, \mathrm{TN}, \mathrm{AP})$. Thus, the nine parameters would be used to derive ERSI.

The parameters of Equation 7 are presented in Table 4. ERSI in every year is as follows (Eq. 8):

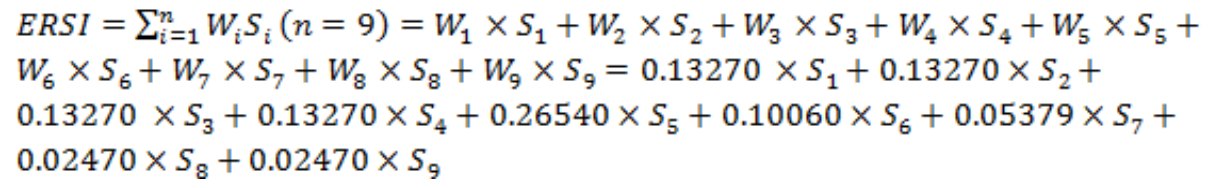

Table 3. Total explaining variances of ecological restoration status in restored coal gangue pile

\begin{tabular}{|c|c|c|c|c|c|c|}
\hline \multirow{2}{*}{ Component } & \multicolumn{3}{|c|}{ Initial eigenvalues } & \multicolumn{3}{|c|}{ Extraction sums of squared loadings } \\
\hline & Total & Variance \% & Cumulative \% & Total & Variance \% & Cumulative \% \\
\hline 1 & 13.984 & 58.269 & 58.269 & 13.984 & 58.269 & 58.269 \\
\hline 2 & 5.301 & 22.086 & 80.354 & 5.301 & 22.086 & 80.354 \\
\hline 3 & 2.834 & 11.810 & 92.164 & 2.834 & 11.810 & 92.164 \\
\hline 4 & 1.301 & 5.422 & 97.587 & 1.301 & 5.422 & 97.587 \\
\hline 5 & .579 & 2.413 & 100.000 & & & \\
\hline 6 & $2.693 \mathrm{E}-15$ & $1.122 \mathrm{E}-14$ & 100.000 & & & \\
\hline 7 & $1.429 \mathrm{E}-15$ & $5.953 \mathrm{E}-15$ & 100.000 & & & \\
\hline 8 & $1.045 \mathrm{E}-15$ & $4.353 \mathrm{E}-15$ & 100.000 & & & \\
\hline 9 & $4.972 \mathrm{E}-16$ & $2.072 \mathrm{E}-15$ & 100.000 & & & \\
\hline 10 & $3.766 \mathrm{E}-16$ & $1.569 \mathrm{E}-15$ & 100.000 & & & \\
\hline 11 & $3.218 \mathrm{E}-16$ & $1.341 \mathrm{E}-15$ & 100.000 & & & \\
\hline 12 & $2.446 \mathrm{E}-16$ & $1.019 \mathrm{E}-15$ & 100.000 & & & \\
\hline 13 & $1.874 \mathrm{E}-16$ & $7.807 \mathrm{E}-16$ & 100.000 & & & \\
\hline 14 & $2.787 \mathrm{E}-17$ & $1.161 \mathrm{E}-16$ & 100.000 & & & \\
\hline 15 & $6.636 \mathrm{E}-18$ & $2.765 \mathrm{E}-17$ & 100.000 & & & \\
\hline 16 & $-6.925 \mathrm{E}-17$ & $-2.885 \mathrm{E}-16$ & 100.000 & & & \\
\hline 17 & $-1.408 \mathrm{E}-16$ & $-5.866 \mathrm{E}-16$ & 100.000 & & & \\
\hline 18 & $-1.929 \mathrm{E}-16$ & $-8.039 \mathrm{E}-16$ & 100.000 & & & \\
\hline 19 & $-2.460 \mathrm{E}-16$ & $-1.025 \mathrm{E}-15$ & 100.000 & & & \\
\hline 20 & $-2.949 \mathrm{E}-16$ & $-1.229 \mathrm{E}-15$ & 100.000 & & & \\
\hline 21 & $-3.195 \mathrm{E}-16$ & $-1.331 \mathrm{E}-15$ & 100.000 & & & \\
\hline 22 & $-5.491 \mathrm{E}-16$ & $-2.288 \mathrm{E}-15$ & 100.000 & & & \\
\hline 23 & $-5.760 \mathrm{E}-16$ & $-2.400 \mathrm{E}-15$ & 100.000 & & & \\
\hline 24 & $-7.019 \mathrm{E}-16$ & $-2.925 \mathrm{E}-15$ & 100.000 & & & \\
\hline
\end{tabular}




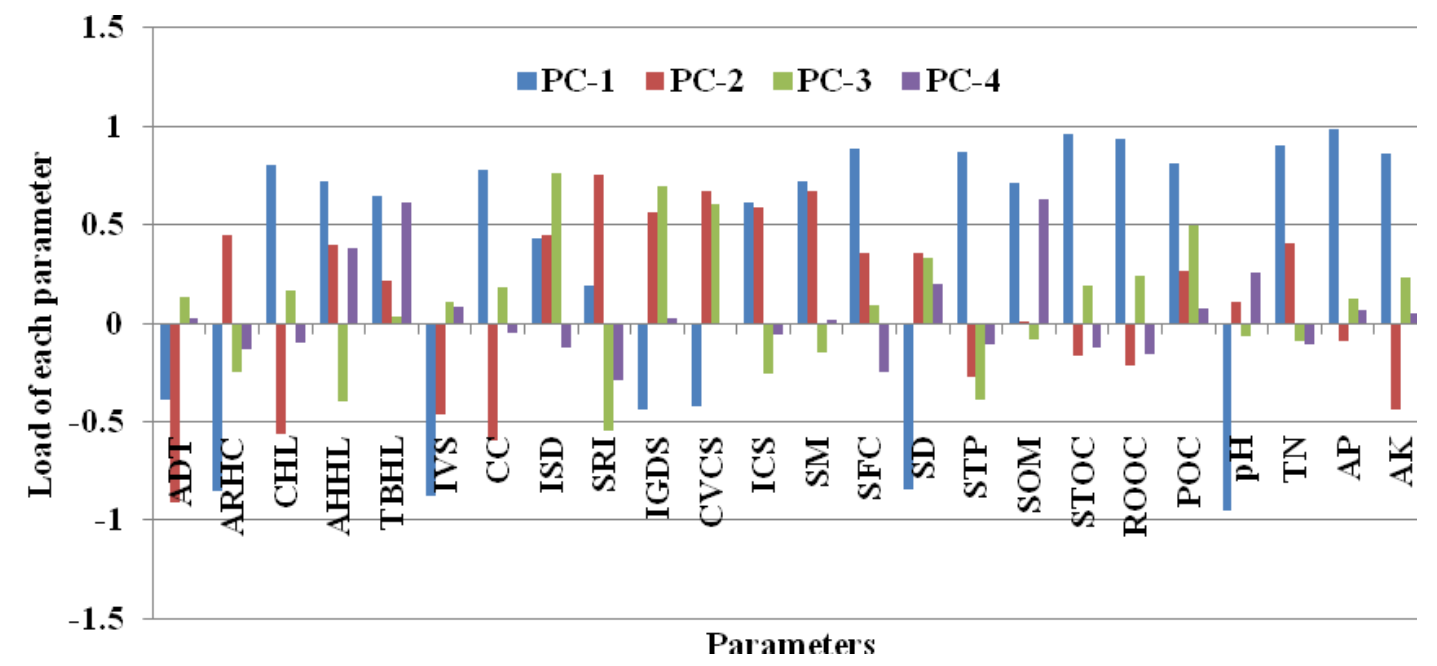

Figure 2. Load of each parameter on PC-1, PC-2, PC-3 and PC-4, respectively. Abbreviations:

The average DBH of trees (ADT), average the ratio height and canopy of trees (ARHC), coverage of the herb layer (CHL), the average height of the herb layer (AHHL), total biomass

of the herb layer (TBHL), the integrity of the vertical structure (IVS), coverage of the community (CC), index of species diversity (ISD), the species richness index (SRI), the index of the growth and decline of species (IGDS), change of value of community similarity (CVCS), the index of community stability (ICS), soil moisture (SM), soil field capacity (SFC), soil density $(S D)$, soil total porosity (STP), soil organic matter (SOM), soil total organic carbon (STOC), readily oxidized organic carbon (ROOC), particulate organic carbon (POC), soil $p H(p H)$, total nitrogen (TN), available phosphorus (AP) and available potassium (AK)

Table 4. The values of parameters in Equation 7 for ecological restoration status in restored coal gangue pile

\begin{tabular}{c|l|c|c|c|c}
\hline Parameters & i & Rang & Type & b & Mean $\left(\mathbf{x}_{\mathbf{i} 0}\right)$ \\
\hline STOC & 1 & $5.979-20.021$ & More is better & -2.5 & 12.437 \\
ROOC & 2 & $0.011-0.037$ & More is better & -2.5 & 0.024 \\
pH & 3 & $7.80-8.50$ & Less is better & 2.5 & 8.230 \\
TN & 4 & $0.042-1.016$ & More is better & -2.5 & 0.230 \\
AP & 5 & $3.850-8.300$ & More is better & -2.5 & 5.815 \\
ADT & 6 & $4.89-11.85$ & More is better & -2.5 & 7.08 \\
ISD & 7 & $2.535-2.902$ & More is better & -2.5 & 2.728 \\
TBHL & 8 & $390.50-621.08$ & More is better & -2.5 & 499.55 \\
SOM & 9 & $23.440-46.360$ & More is better & -2.5 & 33.125 \\
\hline
\end{tabular}

Soil total organic carbon (STOC), readily oxidized organic carbon (ROOC), soil $\mathrm{pH}(\mathrm{pH})$, total nitrogen (TN), available phosphorus (AP), the average DBH of trees (ADT), index of species diversity (ISD), total biomass of the herb layer (TBHL) and soil organic matter (SOM)

The value range: The value range of each parameter is from the minimum to maximum real values

Using the PCA, the contribution of each ecological restoration status parameter to the calculated ERSI in every year is shown in Figure 3. Comparing to other parameters, the contribution of AP was largest in every year and was $0.10,0.07,0.14,0.13$ and 0.14 , respectively. The contribution of $\mathrm{pH}$ ranged from 0.06 to 0.07 . The contributions of STOC and ROOC increased with recovery age (from 0.02 in year 2 to 0.08 in year 5). 
The first year was taken as the benchmark year. The ERSI value (0.25) was lower in year 2 of recovery than that in the benchmark year. ERSI then increased from 0.45 in year 3 to 0.53 in year 5 , more than that in the benchmark year. A significant difference was shown between year 5 and the other years $(P<0.05)$. ERSI of the reference site was the highest (0.65) in Figure 3. A significant difference was shown between the reference site and other years $(P<0.05)$. It was indicated that the ecological restoration status of the restored site would take more time to reach the level of the reference site. A quadratic curve $\left(R^{2}=0.7892\right)$ between ERSI and recovery age is shown in Figure 4. Overall, ERSI increased with recovery age during the early stage of recovery (the first five years) (Fig. 5).

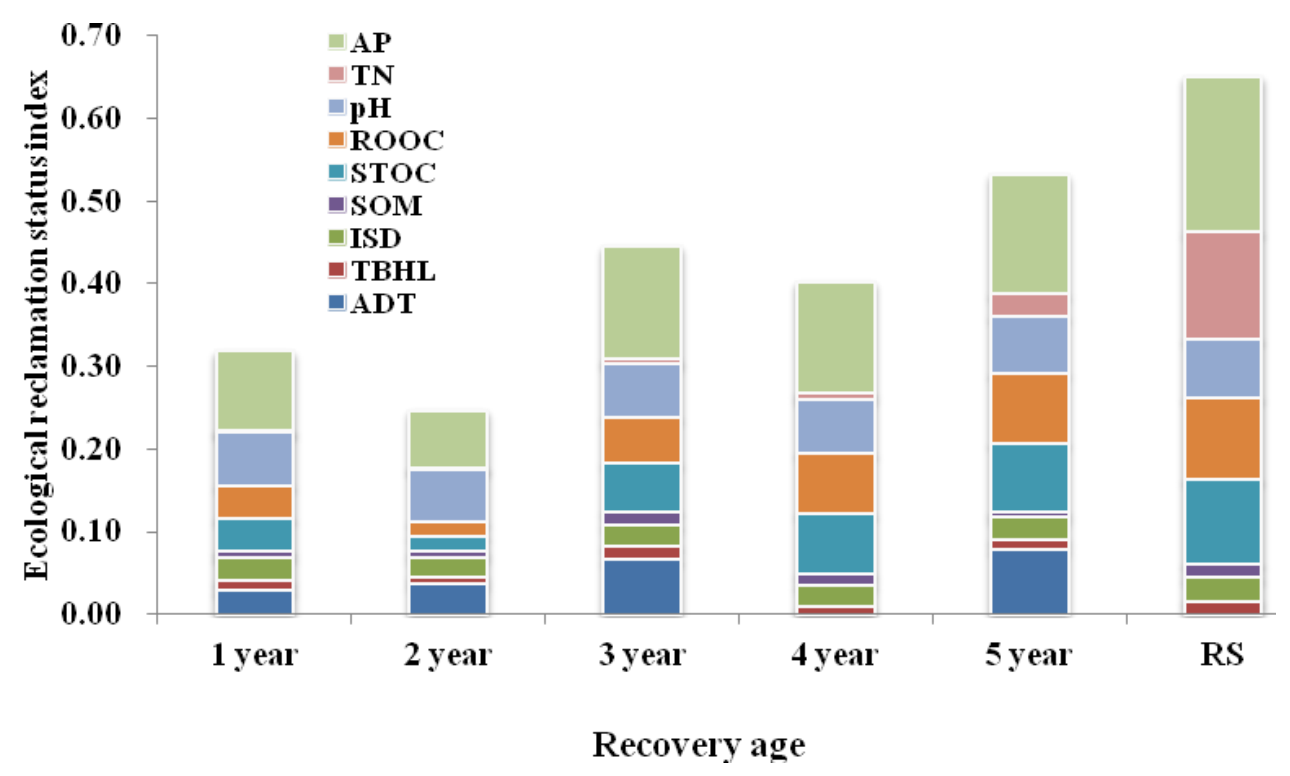

Figure 3. Contribution of each parameter on calculated ERSI. Abbreviations: Soil organic matter (SOM), soil total organic carbon (STOC), readily oxidized organic carbon (ROOC), soil $p H(p H)$, total nitrogen (TN), available phosphorus (AP), average DBH of trees (ADT), index of species diversity (ISD) and total biomass of the herb layer (TBHL). Reference site (RS)

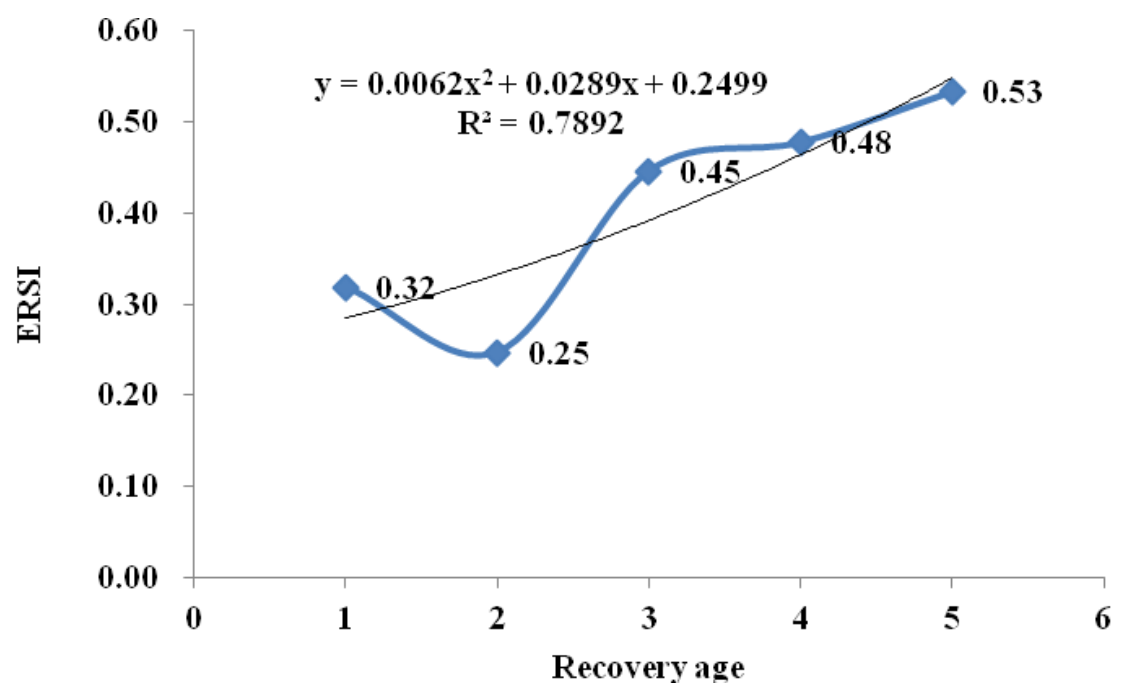

Figure 4. Correlation between recovery age and ERSI 

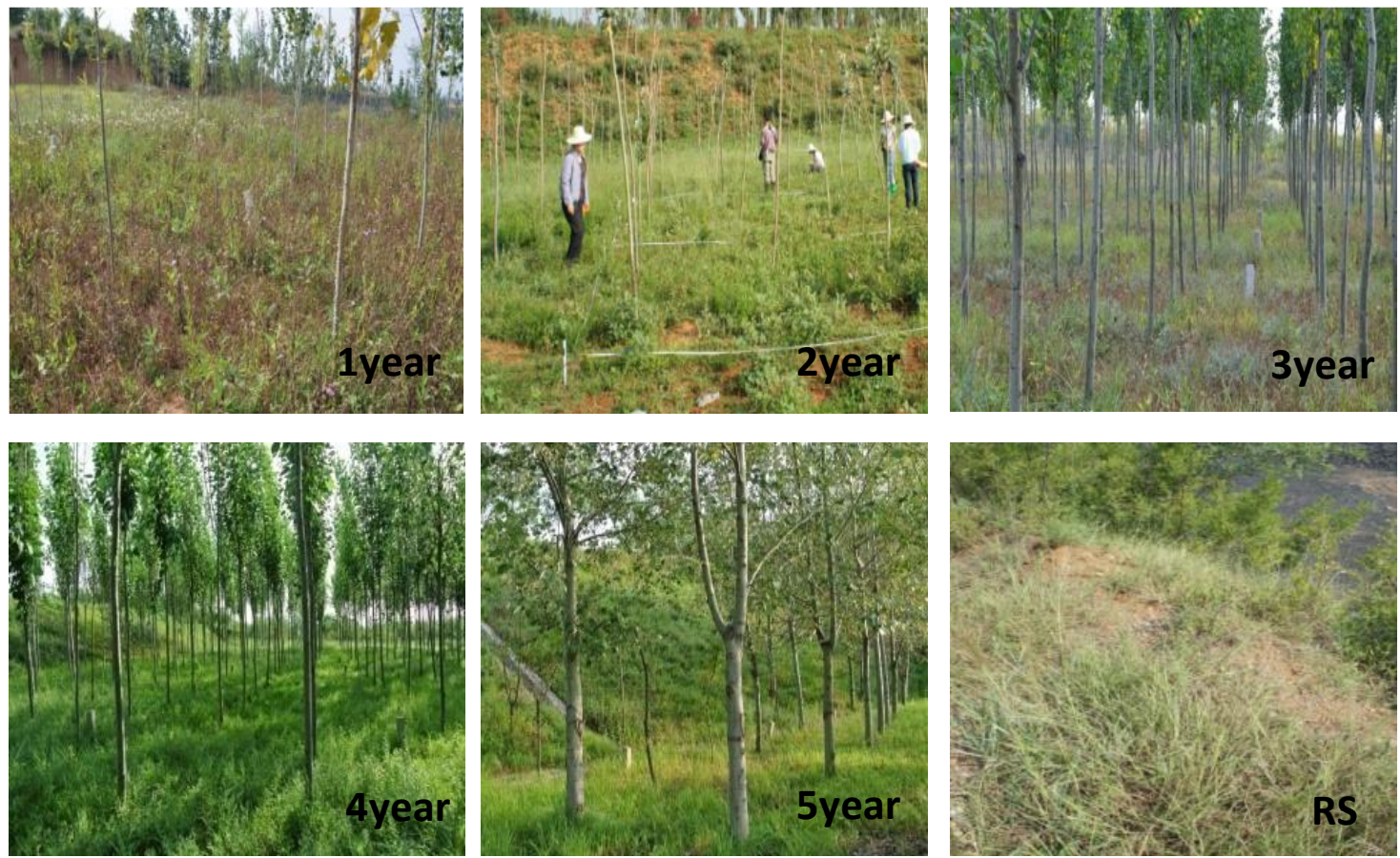

Figure 5. Ecological restoration in every recovery year and RS. Reference site (RS)

\section{Uncertainty analysis of the ERSI by MCS}

To analyze the uncertainty of the ERSI, the study introduced MCS. Based on the distribution function, mean and standard deviation of each parameter in every recovery age in Table 5, 10000 simulations were carried out. 10000 random values of each parameter were generated in every stage. Then based on the Equation 8, 10000 simulations of ERSI were conducted in every stage (Table 6). The uncertainty in 2 year was maximum $( \pm 4.00 \%)$, the largest uncertainty contribution came from the SOM (Table 5). In later years of recovery, the uncertainty became lower. The uncertainty in 5 year was minimum $( \pm 1.89 \%)$. In RS, the uncertainty was $\pm 3.08 \%$.

Table 5. Distributions, means and standard deviations of the parameters in the estimation of ERSI using the MCS

\begin{tabular}{|c|c|c|c|c|c|c|c|c|c|c|c|c|c|}
\hline \multirow[b]{2}{*}{ Parameter } & \multirow[b]{2}{*}{ Distribution } & \multicolumn{2}{|c|}{1 year } & \multicolumn{2}{|c|}{2 year } & \multicolumn{2}{|c|}{3 year } & \multicolumn{2}{|c|}{4 year } & \multicolumn{2}{|c|}{5 year } & \multicolumn{2}{|r|}{$\mathbf{R S}$} \\
\hline & & Mean & $\begin{array}{l}\text { Standard } \\
\text { deviation }\end{array}$ & Mean & $\begin{array}{l}\text { Standard } \\
\text { deviation }\end{array}$ & Mean & $\begin{array}{l}\text { Standard } \\
\text { deviation }\end{array}$ & Mean & $\begin{array}{l}\text { Standard } \\
\text { deviation }\end{array}$ & Mean & $\begin{array}{l}\text { Standard } \\
\text { deviation }\end{array}$ & Mean & $\begin{array}{l}\text { Standard } \\
\text { deviation }\end{array}$ \\
\hline STOC & Normal & 8.74 & 0.4704 & 5.98 & 0.9426 & 11.27 & 0.8169 & 13.37 & 0.9428 & 15.25 & 0.0008 & 20.02 & 2.2314 \\
\hline ROOC & Normal & 0.01 & 0.0014 & 0.01 & 0.0008 & 0.01 & 0.0022 & 0.01 & 0.0009 & 0.01 & 0.0005 & 0.02 & 0.0024 \\
\hline $\mathrm{pH}$ & Normal & 8.46 & 0.0812 & 8.50 & 0.1227 & 8.35 & 0.0821 & 8.24 & 0.1513 & 8.03 & 0.0476 & 7.80 & 0.1071 \\
\hline TN & Normal & 0.05 & 0.0087 & 0.04 & 0.0087 & 0.07 & 0.0062 & 0.08 & 0.0083 & 0.14 & 0.0291 & 0.86 & 0.0212 \\
\hline $\mathrm{AP}$ & Normal & 4.64 & 0.0801 & 3.85 & 0.0962 & 5.97 & 0.1235 & 5.87 & 0.0952 & 6.26 & 0.0423 & 8.30 & 0.1742 \\
\hline ADT & Logistic & 4.89 & 0.4125 & 5.63 & 0.5472 & 9.29 & 1.5489 & 10.80 & 2.2351 & 11.85 & 3.1470 & - & - \\
\hline ISD & Normal & 2.90 & 0.0532 & 2.54 & 0.0470 & 2.62 & 0.0748 & 2.74 & 0.0750 & 2.69 & 0.0936 & 2.88 & 0.0576 \\
\hline TBHL & Logistic & 482.51 & 1.6778 & 398.14 & 0.8990 & 621.08 & 3.4943 & 390.50 & 2.0306 & 484.95 & 1.2511 & 620.13 & 2.4446 \\
\hline SOM & Normal & 15.20 & 0.8870 & 10.31 & 1.0221 & 19.24 & 0.4876 & 23.46 & 1.2110 & 25.37 & 1.2871 & 36.90 & 0.7151 \\
\hline
\end{tabular}

Soil total organic carbon (STOC), readily oxidized organic carbon (ROOC), soil pH (pH), total nitrogen (TN), available phosphorus (AP), the average DBH of trees (ADT), index of species diversity (ISD), total biomass of the herb layer (TBHL) and soil organic matter (SOM). Reference site (RS) 


$$
-11599 \text { - }
$$

Table 6. The ERSI in each recovery age using MCS

\begin{tabular}{c|c|c|c}
\hline Recovery age & Mean & Uncertainty/\% & 95\% Coverage interval \\
\hline 1 year & 0.32 & \pm 3.13 & $0.28-0.36$ \\
2 year & 0.25 & \pm 4.00 & $0.20-0.29$ \\
3 year & 0.45 & \pm 2.22 & $0.40-0.48$ \\
4 year & 0.48 & \pm 2.08 & $0.43-0.51$ \\
5 year & 0.53 & \pm 1.89 & $0.49-0.59$ \\
RS & 0.65 & \pm 3.08 & $0.54-0.69$ \\
\hline
\end{tabular}

Uncertainty: the standard deviation of ERSI value from MCS divided by the arithmetic mean of it. Reference site (RS)

During the different period, the sensitivity of each parameter to ERSI was different (Fig. 6). In years 1 and 2 of recovery, STOC was main influencing factor to ERSI, the sensitivity coefficient of STOC was 0.570 and 0.402 , respectively. In years 3 and 4 of recovery, ROOC was main influencing factor to ERSI, the sensitivity coefficient of ROOC was 0.516 and 0.573 , respectively. The sensitivity coefficient of TN was highest (0.684) in year 5. SOM (0.449) was the most sensitivity factor in RS. It was indicated that at the early stage of recovery, STOC, ROOC and TN played important roles in improving ecological restoration status in coal gangue pile. With the restored area becoming near-nature in adequate time, SOM will play an important role in ecological restoration. It was suggested reasonably supplying STOC, ROOC and TN content will promote ecological restoration process at early stage of recovery.

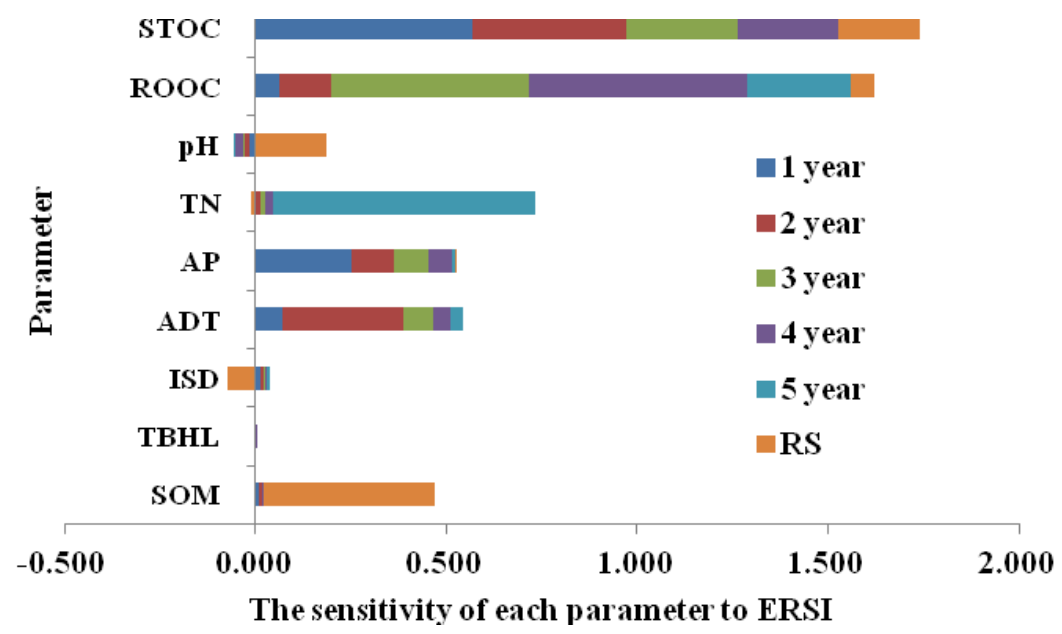

Figure 6. The sensitivity of each parameter to ERSI. Abbreviations: Soil organic matter (SOM), soil total organic carbon (STOC), readily oxidized organic carbon (ROOC), soil $\mathrm{pH}(\mathrm{pH})$, total nitrogen (TN), available phosphorus (AP), average DBH of trees (ADT), index of species diversity (ISD) and total biomass of the herb layer (TBHL). Reference site (RS)

\section{Discussion}

\section{Correlation between plant and soil}

During the early stage of ecological restoration in the coal gangue pile, significantly negative correlation was shown between ADT and SM content because the growth of 
Populus tomentosa consumed more soil moisture. CHL was significantly negatively correlated with SD because herbal roots and litters improved soil porosity. With increasing ADT, CHL and CC, STOC, ROOC, AP and AK increased significantly due partly to heavy litters falling from trees (Populus tomentosa), and herbs decomposed to improve the soil organic carbon, phosphorus and potassium (Sorenson et al., 2011; Mukhopadhyay et al., 2016). It was indicated that Populus tomentosa can be the pioneer species to achieve quick recovery in mining areas (Li and Liber, 2017). ISD was significantly positively correlated with POC, which is probably because dead species bodies improved the POC content (Hao et al., 2015). IGDS was significantly negatively correlated with STP. This was probably because in the benchmark year (year 1), the plant species was the net immigration species, the penetration of plant roots was limited, and STP was low. In the later years, immigration and emigration of species maintained the dynamic balance, IGDS was 1.0-1.1, and STP increased with increasing penetration strength of plant roots (Mukhopadhyay et al., 2016). Lower SM content, better gas porosity and permeability, rich STOC, AP and AK were beneficial to the biomass accumulation of Leymus chinensis and Setaria viridis. Increasing SOM, POC, AP and AK caused an adverse effect on the biomass accumulation of Artemisia lavandulaefolia and Melilotus officinalis. In turn, the accumulation of herb biomass also supplied SOM content in adequate time. Leguminous plants, such as Melilotus officinalis, immigrated and fixed nitrogen to increase TN content (Hao et al., 2015).

\section{Ecological restoration status index (ERSI)}

The parameters system of evaluation comprised six parameters of soil chemical properties and three parameters of basic plant community characteristics. It was suggested that soil chemical properties play a very important role in mine ecological restoration status. The growth of a plant community depends on improved soil chemical properties, such as rich soil nitrogen and organic matter. In turn, the nitrogen fixing capacities of leguminous plants increase TN content. The biomass of plants supplies organic matter to the soil. The basic characteristics of plant community in the restored area as the important parameters that should be included in the ecological evaluation of the recovery status. Mukhopadhyay et al. (2014) also determined six soil parameters, but they were soil physical (2, number of parameters), chemical (2) and biological (2) parameters. Only STOC was a common parameter. The difference of initial parameters resulted in the differences of the other five parameters in both experiments.

Although ADT increased, the total declining content of AP, ROOC, STOC, ISD and TBHL were greater than the increasing content. AP, ROOC and STOC supported rich plant species during the first year. In turn, ISD and TBHL decreased due to the number of species decreasing in year 2 of recovery. A lower score also existed in year 2 of restoration in Mukhopadhyay et al. (2014). It was suggested that the ecological restoration status in year 2 was lower than that in the benchmark year. Trees and herbs grew rapidly with recovery age. Species diversity and community stability were enhanced gradually. Nitrogen fixation of leguminous plants, such as Melilotus officinalis, increased TN content. The total organic carbon increased with the accumulation of vegetation litter and biomass. Moreover, plant roots enriched SOM in the rhizosphere (Montiel-Rozas et al., 2015). AP content also increased from gradual weathering. In turn, the biomass of the herb layer also increased based on the increasing species diversity and soil nutrition with recovery age (Lv and Zheng, 2009). It was suggested that the ecological restoration status in years 3 to 5 was better than that in the 
benchmark year. In Mukhopadhyay et al. (2014), the mine soil quality index (MSQI) reflected the soil properties. In this research, ERSI reflected the results of the interaction between the mine soil and plant community. Their interaction revealed the internal cause of development in mine ecological restoration status.

This time for disturbed mine soil could be at least 20 years based on proper restoration strategy, as reported by Anderson et al. (2008). Orozco-Aceves et al. (2017) suggested that in 22 years, soil physicochemical and key biological properties after restoration still were not recovered to the conditions of the reference soil. In addition, if the restoration method is unsuitable, the restored mining site may remain polluted even 30 years later (Gomez-Ros et al., 2013). The restoration statuses are different in different study sites, climate and restoration methods, etc. However, the reference site was not the final recovery goal. For example, the reference site (natural secondary community) was not the optimal recovery goal in Li (2010). With increasing recovery age, the ecological restoration status in the coal gangue pile would be better than at the reference site (Hao et al., 2016).

We found that a quadratic curve is showed between ERSI and recovery age. It was reported that a positive liner correlation was shown between the mine soil quality index and recovery age (Mukhopadhyay et al., 2014). The different type of correlation might result from the differences of the parameter system and study site. Overall, ERSI increased with recovery age during the early stage of recovery (the first five years). It was indicated that ecological restoration status had a promoted trend during the early stage of recovery (Orozco-Aceves et al., 2017; Mukhopadhyay et al., 2014). This suggested that the functions of the plant-soil system gradually improved with recovery age. However, Li (2010) found that the evaluation result of the ecological restoration status was as follows: year $5>$ year $4>$ year $3>$ reference site $>$ year $1>$ year 2 . The conclusion was different from this study. The causes of this difference were the differences of artificial planting species and the parameter system. For example, in Li (2010), the dominant species of the tree layer was Crataegus pinnatifida, and the parameter system involved soil heavy metal content. In the present research, the dominant species of the tree layer was Populus tomentosa, and soil heavy metal content was uninvolved in the parameter system.

Ecological restoration and natural succession are dynamic processes. At present, artificial vs. natural recovery is controversial for the restoration of coal gangue piles (Woziwoda and Kopec, 2014). This study suggested that artificial recovery (establishing trees) in the first year of recovery, followed by natural herbal recovery in later years, could achieve quick ecological restoration during the early stage of recovery in the mining area. It was suggested that a rapid recovery process could be achieved by reasonable artificial imitation or appropriate interference (Burton et al., 2006; Mudrák et al., 2016). However, it is noteworthy that if invasive alien species are planted in the process of artificial restoration in the mining area, the opposite effect may occur (Holl, 2002). Thus, considering the magnitude of the problem and developing each restoration method are essential steps to evaluate the status of ecological restoration at restored sites (Gomez-Ros et al., 2013).

ERSI was developed based on the plant-soil system of a restored coal gangue pile in the first five years of recovery. The first year was taken as the benchmark year. By comparing the ERSI value in every year of recovery to that in the benchmark year, the ecological restoration status was evaluated. Long-term monitoring the plant-soil system 


$$
-11602 \text { - }
$$

will be the focus of further research. ERSI could play a positive demonstration and radiation role in the future evaluation of ecological restoration status in mining areas.

\section{Conclusions}

The parameter system for evaluation of ecological restoration status in restored coal gangue piles was established on the basic plant community characteristics and soil physicochemical properties. Principal component analysis (PCA) was employed to derive an ecological restoration status index (ERSI). ERSI was developed based on the parameter system of the plant-soil system in a restored coal gangue pile during the early stage of recovery (the first five years of recovery). The first year was taken as the benchmark year. By comparing the ERSI value in every year of recovery to that in the benchmark year, the ecological restoration status was evaluated. Except for year 2, the ecological restoration status in years 3 to 5 of recovery and the reference site were better than that in the benchmark year. ERSI reflected the results of the interaction between the mine soil and plant community. Overall, ERSI increased with recovery age during the early stage of recovery.

With recovery age, the uncertainty of ERSI showed decreased trend by MCS, and the sensitivity of each parameter to ERSI was different. At the early stage of recovery, STOC, ROOC and TN played important roles in improving ecological restoration status in coal gangue pile.

Acknowledgments. This work was supported by the Project of Tianjin Science and Technology Planning of China (grant no. 18ZXSZSF00200), the Research and Development Project by Lu'an Mining Group Limited Liability Company of China (grant no. 1103100301), and the Technology Special Commissioner Project of Tianjin Natural Science Fund of China (grant no. 16JCTPJC53900). The authors thank all the assistors for their kind help.

Conflict of interests. The authors declare that they have no conflict of interests.

\section{REFERENCES}

[1] Ahirwal, J., Maiti, S. K., Reddy, M. S. (2017): Development of carbon, nitrogen and phosphate stocks of reclaimed coal mine soil within 8 years after forestation with Prosopis juli ora (Sw.) Dc. - Catena 156: 42-50.

[2] Alvey, S., Yang, C. H., Buerkert, A., Crowley, D. E. (2003): Cereal/legume rotation effects on rhizosphere bacterial community structure in West African soils. - Biology and Fertility of Soils 37: 73-82.

[3] Anawar, H. M., Hossain, M., Canha, N., Santa-Regina, I., Freitas, M. C. (2013): Adaptation, tolerance, and evolution of plant species in a pyrite mine in response to contamination level and properties of mine tailings: sustainable rehabilitation. - Journal of Soils and Sediments 13: 730-741.

[4] Anderson, J. D., Ingram, L. J., Stahl, P. D. (2008): Influence of reclamation management practices on microbial biomass carbon and soil organic carbon accumulation in semiarid mine lands of Wyoming. - Applied Soil Ecology 40: 387-397.

[5] Bodlák, L., Křováková, K., Nedbal, V., Pechar, L. (2012): Assessment of landscape functionality changes as one aspect of reclamation quality - the case of Velká podkrušnohorská dump, Czech Republic. - Ecological Engineering 43: 19-25. 
[6] Bouzon, M., Govindan, K., Rodriguez, C. M. T., Campos, L. M. S. (2016): Identification and analysis of reverse logistics barriers using fuzzy Delphi method and AHP. Resources Conservation and Recycling 108: 182-197.

[7] Burton, C. M., Burton, P. J., Hebda, R., Tumer, N. J. (2006): Determining the optimal sowing density for mixture of native plants used to revegetate degraded ecosystems. Restoration Ecology 14: 379-390.

[8] Elgersma, A. M. (1998): Primary forest succession on poor sandy soils as related to site factors. - Biodiversity and Conservation 7: 193-206.

[9] Godron, M. (1972): Some aspects of heterogeneity in grasslands of Cantal. - Statistical Ecology 3: 397-415.

[10] Gomez-Ros, J. M., Garcia, G., Penas, J. M. (2013): Assessment of restoration success of former mental mining areas after 30 years in a highly polluted Mediterranean mining area: Gartagena-La Union. - Ecological Engineering 57: 393-402.

[11] Hao, J., Guo, D. G., Shangguan, T. L., Zhang, J., Liu, W. H., Zhang, P. P. (2015): Changes in soil factors at early stage of spontaneous herbal recovery in a Coal Gangue Yard. - Bangladesh Journal of Botany 44(5): 689-697.

[12] Hao, J., Guo, D. G., Shangguan, T. L., Liu, W. H., Zhang, J., Zhang, P. P. (2016): Ecological performance assessment on early plant reclamation in coal gangue yard. Acta Ecologica Sinica 36: 1946-1958.

[13] Holl, K. D. (2002): Long-term vegetation recovery on reclaimed coal surface mines in the eastern USA. - Journal of Applied Ecology 39: 960-970.

[14] Krumins, J. A., Goodey, N. M., Gallagher, F. (2015): Plant-soil interactions in metal contaminated soils. - Soil Biology \& Biochemistry 80: 224-231.

[15] Li, J. F. (2010): Study on Quality assessment of ecological restoration in mine Derelict land in Beijing. - Doctorate Dissertation, Beijing Forestry University, Beijing.

[16] Li, S. Q., Liber, K. (2017): Influence of different revegetation choices on plant community and soil development nine years after initial planting on a reclaimed coal gob pile in the Shanxi mining area, China. - Science of the Total Environment. https://doi.org/10.1016/j.scitotenv.2017.09.252.

[17] Licina, V., Aksic, M. F., Colic, S., Zec, G. (2013): A bioassessment of soil nickel genotoxic effect in orchard planted on rehabilitated coalmine overburden. Ecotoxicology and Environmental Safety 98: 374-382.

[18] Liu, Y. G. (2011): Evaluation of artificial restoration effect of the abandoned mines in Beijing. - Doctorate Dissertation. Beijing Forestry University, Beijing.

[19] Lv, C. H., Zheng, F. L. (2009): Evaluation of soil quality during vegetation restoration in the Ziwuling Area of Loess Plateau. - Science of Soil and Water Conservation 7: 12-18.

[20] Mark, T., David, M., Patrick, A. (2012): Recent advances in restoration ecology: Examining the modern Australian agro-ecological and post-mining landscapes. Agriculture Ecosystems \& Environment 163: 1-2.

[21] Montiel-Rozas, M. M., Madejón, E., Madejón, P. (2015): Evaluation of phytostabilizer ability of three ruderal plants in mining soils restored by application of organic amendments. - Ecological Engineering 83: 431-436.

[22] Mudrák, O., Doležal, J., Frouz, J. (2016): Initial species composition predicts the progress in the sonptaneous succession on post-mining sites. - Ecological Engineering 95: 665670 .

[23] Mukhopadhyay, S., Maiti. S. K., Masto, R. E. (2014): Development of mine soil quality index (MSQI) for evaluation of reclamation success: a chronosequence study. Ecological Engineering 71: 10-20.

[24] Mukhopadhyay, S., Masto, R. E., Yadav, A., George, J., Ram, L. C., Shukla, S. P. (2016): Soil quality index for evaluation of reclaimed coal mine spoil. - Science of the Total Environment 542: 540-550. 
[25] Orozco-Aceves, M., Tibbett, M., Standish, R. J. (2017): Correlation between soil development and native plant growth in forest restoration after surface mining. Ecological Engineering 106: 209-218.

[26] Ott, T., Van Aarde R. J. (2014): Coastal dune topography as a determinant of abiotic conditions and biological community restoration in northern KwaZulu-Natal, South Africa. - Landscape \& Ecological Engineering Official 10: 17-28.

[27] Parraga-Aguado, I., Gonzalez-Alcaraz, M. N., Alvarez-Rogel, J., Jimenez-Carceles, F. J., Conesa, H. M. (2013): The importance of edaphic niches and pioneer plant species succession for the phytomanagement of mine tailings. - Environmental Pollution 176: 134-143.

[28] Pietrzykowski, M., Chodak, M. (2014): Near infrared spectroscopy-A tool for chemical properties and organic matter assessment of afforested mine soils. - Ecological Engineering 62: 115-122.

[29] Rossini-Oliva, S., Mingorance, M. D., Monaci, F., Valdés, B. (2016): Ecophysiological indicators of native Cistus ladanifer L. at Riotinto mine tailings (SW Spain) for assessing its potential use for rehabilitation. - Ecological Engineering 91: 93-100.

[30] Sena, K., Barton, C., Hall, S., Angel, P., Agouridis, C., Warner, R. (2015): Influence of spoil type on afforestation success and natural vegetative recolonization on a surface coal mine in Appalachia, United States. - Restoration Ecology 23: 131-138.

[31] Sorenson, P. T., Quideau, S. A., Mackenzie, M. D., Landhäusser, S. M., Oh, S. W. (2011): Forest floor development and biochemical properties in reconstructed boreal forest soils. - Applied Soil Ecology 49: 139-147.

[32] Su, M. (2010): Test study on soil nutrient cycling of coal mining subsidence area and its impact on the ecological environment. - Master Dissertation. Hebei University of Engineering, Handan.

[33] Tripathi, N., Singh, R. S., Hills, C. D. (2016): Soil carbon development in rejuvenated Indian coal mine spoil. - Ecological Engineering 90: 482-490.

[34] Woziwoda, B., Kopec, D. (2014): Afforestation or natural succession? Looking for the best way to manage abandoned cut-over peatlands for biodiversity conservation. Ecological Engineering 63: 143-152.

[35] Xie, Y. G., Che, J. X., Sun, W. B., Peng, X. (2012): Comparison study of mining subsidence years on soil physical properties of in mining area. - Research of Soil \& Water Conservation 19(4): 26-29.

[36] Yao, G. Z., Yang, T. T. (2014): Research on ecological evaluation system of environment governance in mining area. - Western Resources 2: 173-175.

[37] Zeng, Y. H., Liu, L. M., Zhang, H., Do, D. D., Nicholson, D. (2018): A Monte Carlo study of adsorption-induced deformation in wedge-shaped graphitic micropores. Chemical Engineering Journal 346: 672-681.

[38] Zhang, C. X., Xu, L., Zhou, X. D. (2007): Land suitability assessment $f$ vegetation restoration of the coal gangue pile of Fuxin mine area. - Research of Soil \& Water Conservation 14: 246-248.

[39] Zhang, X. W. (2006): Researches on the succession order of the soil and vegetation in the abandoned field of the mining area in the semi-arid region. - Master Dissertation. Liaoning Technical University, Fuxin.

[40] Zhao, X. W., Jia, S. H., Li, M., Liu, Y., Su, T. C. (2014): Soil quality assessment by TOPSIS method based on PCA in the afforested coal gangue area. - Journal of Northeast Forestry University 2: 98-102. 